\title{
Coping of Young Refugees in Germany
}

\section{Relations to Gender, Age, and Gender Role Attitudes}

\author{
Hannah Nilles ${ }^{1} \mathbb{0}$, Denise Kerkhoff ${ }^{1,2}$, Zeynep Demir ${ }^{3}$, Johanna Braig ${ }^{4}$, Pia Schmees ${ }^{4} \oplus$, \\ Jana-Elisa Rueth ${ }^{1}$, Heike Eschenbeck ${ }^{4}$, and Arnold Lohaus ${ }^{1}$ \\ ${ }^{1}$ Department of Developmental Psychology, Bielefeld University, Germany \\ ${ }^{2}$ Department of Psychology, University of Konstanz, Germany \\ ${ }^{3}$ Institute for Interdisciplinary Research on Conflict and Violence, Bielefeld University, Germany \\ ${ }^{4}$ Department of Educational Psychology and Health Psychology, University of Education Schwäbisch Gmünd, Germany
}

\begin{abstract}
Background: Coping is considered to have an important influence on well-being, especially in adolescent refugees dealing with a high amount of stress. In addition, gender differences in coping are a common topic for research and are often attributed to differences in socialization between boys and girls. Aims: The study aims at clarifying the gender differences in coping strategies used by non-Western adolescents. Additionally, associations with aspects of socialization, in particular Gender Role Attitudes (GRA), on gender differences are investigated. Method: Refugees from Syria, Iraq, and Afghanistan ( $N=106,55 \%$ male) aged 11-18 years completed questionnaires in schools or housing facilities. Associations between gender, GRA, coping strategies, and well-being were investigated using moderation and regression analyses. Results: Gender differences found in previous literature could, in part be replicated. Refugee girls reported more anger-related emotion regulation than boys did. However, GRA did not show any connections to coping strategies. Limitations: Most limitations result from low reliabilities and possible biases due to the use of self-reports. Conclusion: The more frequent use of anger-related emotion regulation as the only gender difference replicated in this study highlights the importance of research with refugee samples to prevent over-generalization of previous results from Western cultures.
\end{abstract}

Keywords: coping, refugees, adolescents, gender role attitudes

The way adolescents deal with stress has been well-known to influence their well-being and adjustment (Alzoubi et al., 2019; Broderick \& Korteland, 2002). Its importance is amplified in groups facing numerous disadvantages, for example, refugee children and adolescents (Fazel et al., 2012; Lustig et al., 2004). Minor refugees face a wide range and high amount of stressful situations, from potentially traumatic events during all phases of their migration (Lustig et al., 2004) to daily hassles that may or may not be related to their migration background. All this may happen while facing the developmental challenges of adolescence (Bronstein \& Montgomery, 2011; Fazel et al., 2012). However, migration cannot solely be seen as a risk factor; it may also influence the way adolescents deal with stressful situations while navigating the times of transition into new homes and from child- to adulthood. A significant number of studies focus on severe life events faced by refugees (Fazel et al., 2012; Hynie, 2018), which can interact with strategies used to deal with different stressful situations (Benson et al., 2011). However, daily life events and stressors are considered to be equally important for adjustment and successful developmental outcomes (for a review, see Bronstein \& Montgomery, 2011). Therefore, this study addresses coping with a potential everyday stressor not unique to refugees but common to adolescents from all cultural backgrounds: an argument with a close friend (Persike \& Seiffge-Krenke, 2016). Following the transactional stress theory by Lazarus and Folkman (1984), a person may use different problem- or emotion-focused coping strategies to deal with such potential social stressors. The person might try to sort out the problem, avoid the friend, or talk about the argument with other people. Lazarus and Folkman (1984) also introduced factors influencing coping strategies such as age and gender of the person.

While the literature on age differences in coping is relatively clear, results are less conclusive regarding gender differences. With higher age, children and adolescents widen their range of coping strategies and improve their ability to use them (Zimmer-Gembeck \& Skinner, 2011). In contrast, many studies tried to establish a relationship between gender and coping strategies commonly used by adolescents, but results have been inconclusive (Cicognani, 2011; Eschenbeck et al., 2007). 


\section{Coping Strategies and Gender}

While some studies found men employing more active and problem-focused strategies and women employing more passive and emotion-focused strategies (Hobfoll et al., 1994). Other studies found boys to use more avoidance coping and girls using more social support and problem solving (Eschenbeck et al., 2007). In contrast, Tamres et al. (2002) found that overall, women reported more use of coping regardless of the strategies used. In part, these mixed findings result from different approaches to categorize coping strategies (Compas et al., 2001; Tamres et al., 2002; Zimmer-Gembeck \& Skinner, 2011). Lazarus and Folkman (1984) only distinguished between two broad categories of coping strategies: problem-focused and emotion-focused coping. Other systems for categorizing coping strategies were developed and tested for gender differences (Washburn-Ormachea et al., 2004), such as active and passive coping. As findings remained inconclusive, the focus switched from broader categories to actual behaviors to cope with stressful situations. This approach is helpful as coping strategies such as social support include behaviors that fall in more than one broader classification. Eschenbeck et al. (2012) developed a five strategy framework via factor analyses based on the most commonly described and tested coping strategies. The factors are anger-related emotion regulation, palliative emotion regulation, seeking social support, avoidance coping, and problem-solving. Studies using this approach commonly reported gender differences in the use of social support, with girls employing this strategy more often (Beck et al., 2016; Eschenbeck, 2010; Eschenbeck et al., 2007, 2018). In contrast, boys used more avoidance coping (Beck et al., 2016; Eschenbeck, 2010).

While a huge body of literature based on Western samples found different coping strategies and factors that influence the choice of coping strategies, including gender (Beck et al., 2016; Brems \& Johnson, 1989; Eschenbeck et al., 2007), it remains unclear to which extent those results can be generalized to adolescents of other cultures (Malooly et al., 2017).

Based on their previous findings, Eschenbeck et al. (2012) and Kohlmann et al. (2012) conducted a study to test the cross-cultural applicability of their classification and gender differences with German and Turkish adolescents. In both studies, gender differences in general and differences between the cultures were attributed to the influence of socialization, following the notion that gendered behavior is learned through a child's immediate and broader environment. This approach follows the socialization hypothesis, a common explanation for gender differences in coping strategies (Felsten, 1998). The hypothesis states that men and women start to learn from early on behaviors that are acceptable for each gender, including coping strategies.

\section{Socialization}

Following the socialization hypothesis, gender is not the only factor influencing the choice of coping strategies. Closely related to gender is what girls and boys learn from their social environment about appropriate behaviors and roles for coping with stressful situations in general and for each gender. They might learn stereotypical behavior, such as women being more emotional and talkative. At the same time, boys might be taught to either deny a problem or use a practical approach to deal with it (Copeland \& Hess, 1995). Following these stereotypes and expectations, women should show more social support strategies while men focus on proactive problem solving or avoidance, a pattern found by Eschenbeck et al. (2007). Children learn these gender roles, stereotypes, and expectations early on from their families, peers, and members of the society around them. Washburn-Ormachea et al. (2004) point out that different disciplines provided evidence for cultural differences in gender roles. Those differences threaten the generalizability of gender differences discovered in Western samples highlighting the need for cross-cultural research (Kohlmann et al., 2012; Torsheim et al., 2006). In contrast to most previous studies, the present study aims to examine gender differences in coping strategies and assess the influence of socialization by investigating the gender role attitudes of adolescents from Syria, Afghanistan, and Iraq. The traditional distribution of these roles is described by the breadwinner-caregiver model (Barry \& Beitel, 2006), where the man provides the family with financial means. In contrast, the woman takes care of the household and any children or elders. This model can be found in different cultures, for example, in the Syrian (Alzoubi et al., 2019). Gender role attitudes (GRA) are defined as the way people think about these roles. A traditional GRA links behaviors and social roles to a certain gender following the previously described model. Adherence to more traditional roles is interpreted as a more traditional GRA and rigid view on gender and the appropriateness of specific behaviors for men and women (Hobfoll et al., 1994).

As many of the well-established measurements of social roles are outdated or focus on only one gender, a questionnaire based on the social constructivist hypothesis was chosen in this study (Baber \& Tucker, 2006). The social constructivist hypothesis states that gender is constructed by society and is therefore assumed to be culture-sensitive. Furthermore, the approach allows participants to express their agreement with traditional gender roles and their opinion about the division itself on the so-called 
gender-transcendent attitude scale (e.g., the distribution of chores by gender of family members). Studies show that females tend to display less traditional roles than males, suggesting an interaction between gender and GRA (AlBahrani et al., 2013; Baber \& Tucker, 2006).

\section{Well-Being and Coping}

The most favorable outcome of coping is adaptation. By successful coping, the adolescent reaches a state of reduced stress and increased somatic and psychological well-being. Gender differences in coping might also contribute to differences in well-being, which can be defined as an optimum of psychological functioning and experience (Ryan \& Deci, 2001). Studies have shown that women and girls report less well-being, which might be due to gender-specific coping behaviors (Cavallo et al., 2015; Hampel \& Petermann, 2005). Some studies found the association of single coping strategies to well-being more pronounced for one of the genders, therefore having a potentially stronger connection to the well-being of girls or boys (Piko, 2001; Wilson et al., 2005). Piko (2001) found social support to be positively connected to well-being for both genders, but it was a stronger predictor for well-being in boys than in girls. A study by Wilson et al. (2005) indicates that problem-focused coping was connected to positive symptoms (e.g., vigor) in girls, but also negative symptoms (e.g., tension) in boys, while avoidance coping had negative effects on both genders, but more severe effects on girls. Therefore, the association of coping and well-being might be moderated by gender. Following these results, the present study examines possible differential associations between the coping strategies seeking social support, palliative emotion regulation, anger-related emotion regulation, avoidance coping, problem-solving, and the well-being of each gender.

\section{Research Questions and Hypotheses}

This study aims to replicate previous findings of associations between specific coping strategies and gender while examining the possible moderation of these associations by GRA in young refugees from Syria, Afghanistan, and Iraq. Furthermore, the study aims at identifying different associations of the coping strategies of boys and girls with their well-being. To account for possible age influences (Zimmer-Gembeck \& Skinner, 2011) and the length of stay in the host country, which is considered a possible influence on well-being, these variables were included as control variables in all hypotheses (Fazel et al., 2012). Furthermore, to control for possible dependencies, country of origin was included as well.

In line with previous research, it is assumed that adolescents show gender-specific preferences for coping strategies when dealing with a potential social stressor (Hypothesis 1). Moreover, gender-linked and gender-transcendent role attitudes are assumed to moderate the association between gender and coping strategies (Hypothesis 2). In addition, it is expected that the association between coping strategies and well-being is different for boys and girls (Hypothesis 3).

\section{Method}

\section{Sample}

The sample was collected as part of the YOURGROWTH project, a study on the development of minor refugees in Germany. An ethics approval was issued for the project by the Ethics Commission of Bielefeld University. Data collection for the sample used in this study was conducted between January 2019 and May 2020 in schools or refugee housing facilities around Bielefeld and Stuttgart. The data collection was interrupted when group sampling was no longer possible because of the COVID-19 pandemic. Participants filled out questionnaires (provided in German as well as Arabic, Persian, Kurmanci, and Sorani) on a tablet in the presence of an investigator, if without the feasible one speaking the mother language of the participants. They were compensated with a $€ 20$ voucher. As questionnaires used for the present research questions were only given to participants at secondary schools (or children and adolescents aged 12 and older), a subsample of 200 participants of the YOURGROWTH sample remained. A total of 94 participants ( $47 \%$ of the subsample) were excluded because of more than $20 \%$ missing values on any of the scales used. Due to the high drop-out rate, analyses were conducted to investigate possible evidence of a systematic drop-out. Differences between the subsample included in the study and those excluded from the study were tested regarding age, gender, and length of stay. There was no significant difference between included and excluded participants. Therefore, the following analyses were conducted with a remaining sample of $N=106$. The mean age of the sample was $M=14.42$ years, $S D=1.82$ (range: $11-18$ years). The gender ratio was approximately balanced with $45 \%$ girls and $55 \%$ boys ( $0 \%$ other). No unaccompanied refugees were part of the sample. Most participants came from Syria $(55 \%)$ and Iraq (35\%), with the smallest subgroup migrating from Afghanistan (10\%).

\section{Measurements}

The complete questionnaire consisted of a variety of measurements for different constructs investigated by the YOURGROWTH project. Only those questionnaires of relevance for this study will be introduced in detail. 


\section{Demographic Information}

Participants provided information on their age and specified their gender as male, female, or other. Length of stay was originally measured on a scale ranging from 1 month to more than 36 months in steps of 3 months but was adapted as participants had difficulties picking an answer. Answer options were rephrased, and earlier responses were transferred into a new format ranging from $1=$ less than half a year to $6=$ more than 5 years in 1-year steps. Country of origin could be indicated as Syria, Iraq, Afghanistan, or other.

\section{Coping Strategies and Well-Being}

A shortened version of the Revised German Stress and Coping Questionnaire for Children and Adolescents (Eschenbeck et al., 2006) was used to assess the coping strategies. Participants rate the frequency (ranging from $1=$ never to $5=$ almost always) with which they engage in coping behavior after a potential social stressor (argument with a close friend). This scenario was chosen as previous studies showed a more pronounced gender difference in adolescents' coping with this type of stressful situation (Eschenbeck et al., 2007, 2018). The five coping strategies are seeking social support (e.g., "I ask someone for help"; Cronbach's $\alpha=.66$ ), problem solving (e.g., "I try to think of different ways to solve it"; $\alpha=.77$ ), avoidant coping (e.g., "I tell myself it doesn't matter"; $\alpha=.52$ ), palliative emotion regulation (e.g., "I try to relax"; $\alpha=.71$ ), and anger-related emotion regulation (e.g., "I get mad and break something"; $\alpha=.58$ ). Each scale comprises five items. The well-being scale included in the SSKJ 3-8-R consists of four items (e.g., "How many times did you feel happy last week?"; $\alpha=.68)$ which are rated on a 3 -point scale $(1=$ not once, 2 = once, 3 = several times per week). Total sum scores were computed for all coping scales and the wellbeing scale when no more than one item was missing. After excluding participants with too many missing values, as described previously, no responses were missing.

\section{Gender Role Attitudes}

A German translation of the Social Role Questionnaire (SRQ; Baber \& Tucker, 2006) was used to measure GRA. Participants ranked their approval to 13 different statements from 0\% (= strongly disagree) to $100 \%$ (= strongly agree). Eight statements belong to the gender-linked scale $(\alpha=.72)$, the remaining five constitute the gender-transcendent scale $(\alpha=.61)$. While the first scale measures genderlinked attitudes (e.g., "Mothers should work only when necessary"), the latter measures gender-transcendent attitudes (e.g., "People can be aggressive and nurturing regardless of their sex" - reverse coded). For both scales, lower scores indicate less traditional attitudes. Sum scores for both scales were calculated if no more than two items of the gender-linked or no more than one item from the gendertranscendent scale were missing.

\section{Statistical Analyses}

Overall, $9.5 \%$ of the data in the remaining sample was missing, with none missing in the coping strategy scales. The remaining missing values were replaced by multiple imputation with the mice package in R (Van Buuren \& Groothuis-Oudshoorn, 2011), following guidelines for multiple imputation with predictive mean matching and an iteration of five. Interactions for the moderation were imputed following the Just another Variable approach (Van Buuren \& Groothuis-Oudshoorn, 2011). All analyses were conducted in R Version 4.0.3 ( $\mathrm{R}$ Core Team, 2020).

Each coping strategy was regressed on the other strategies to account for the shared variance of the strategies and their intercorrelations. The residuals of each regressed coping strategy were then used in the following analyses, these residuals are referred to as coping strategies to facilitate readability. To determine the association of each coping strategy with gender as stated in Hypothesis 1 and the possible moderation by gender role attitudes as stated in Hypothesis 2, hierarchical multiple regression analyses with three steps were conducted, one for each coping strategy. Each model was built in the same order: First, to control for the possible influence of age and the length of stay and possible dependencies based on the country of origin (dummy coded, Afghanistan as the reference), these variables were included at step one. In step two, gender was introduced as a predictor to test Hypothesis 1. Gender was dummy coded, with girls being the reference category. Third, to test the moderation stated by Hypothesis 2, both GRAs, as well as their interaction with gender, were added in step three. The scores of the gender-linked and gendertranscendent scales were mean-centered for their use as moderators. Requirements for calculating the regression and moderation analyses were met.

An additional hierarchical regression with well-being as dependent variable was modeled to test Hypothesis 3. Again, the first step controlled for age, length of stay, and country of origin. In step two, the residuals of the coping strategies were added as predictors. In the third and final step, gender and the interactions of gender with each coping strategy were added.

\section{Results}

\section{Preliminary Analyses}

Table 1 shows the means and standard deviations for boys and girls regarding their age, their reported use of coping 
Table 1. Means $(M)$ and standard deviations $(S D)$ for boys and girls

\begin{tabular}{lrrrrr}
\hline & \multicolumn{2}{c}{ Girls } & & \multicolumn{2}{c}{ Boys } \\
\cline { 2 - 3 } \cline { 6 - 7 } Scale & $M$ & $S D$ & & $M$ & $S D$ \\
\hline Age & 14.12 & 1.84 & & 14.67 & 1.78 \\
Length of Stay & 2.94 & 1.36 & & 3.71 & 1.28 \\
Gender-linked & 53.90 & 14.56 & & 53.91 & 10.78 \\
Gender-transcendent & 13.14 & 8.58 & & 15.52 & 8.21 \\
Anger-related ER & 11.22 & 3.36 & & 8.89 & 2.60 \\
Social support & 14.58 & 4.20 & & 13.59 & 4.05 \\
Problem solving & 17.43 & 4.94 & 17.20 & 4.23 \\
Avoidance coping & 14.77 & 3.27 & & 14.31 & 3.90 \\
Palliative ER & 16.33 & 3.36 & & 16.07 & 4.72 \\
Well-being & 9.79 & 2.00 & & 9.86 & 2.16 \\
\hline
\end{tabular}

Note. ER = Emotion regulation. Length of stay was reported in years. Possible answers ranged from 0 to 100 in ten steps for Gender-linked and Gender-transcendent scale, from 1 to 5 for coping scales, and 1 to 4 for the well-being scale.

strategies, their attitudes towards gender roles, and their well-being. On average, boys were in Germany significantly longer than girls, $t(83.79)=3.12, p=.002$. Girls showed a significantly higher mean on anger-related emotion regulation, $t(102.05)=-3.88, p<.000$. None of the other means was significantly different between the genders.

Table 2 shows the correlations between all variables. The highest correlation was found between the gender-linked and gender-transcendent scales of the SRQ followed by correlations of palliative emotion regulation seeking social support, problem-solving, avoidance coping, and age. Furthermore, seeking social support was correlated with problem-solving.

\section{Main Analyses}

To test the hypothesis that gender is associated with using different coping strategies (Hypothesis 1) and the moderation of these associations with GRA (Hypothesis 2), five hierarchical multiple regression analyses, one for each of the coping strategies, were conducted.

\section{Control for Age, Length of Stay, and Country of Origin}

Step one of the hierarchical multiple regressions (Table 3; Tables E1-E4 in Electronic Supplementary Material 1, ESM 1) included age, length of stay, and country of origin to control for possible influences of these variables. Only palliative emotion regulation (see Table E4 in ESM 1) was significantly predicted by age, with older adolescents using palliative emotion regulation more often. However, for none of the coping strategies (including palliative emotion regulation) did the first step explain a significant amount of variance.

\section{Coping Strategies and Gender (Hypothesis 1)}

As shown in Table 3, only step two of the model of angerrelated emotion regulation could explain a significant amount of variance in the use of coping strategies by including gender, $F(1,102)=15.73, p=.017$. Hence, anger-related emotion regulation was significantly predicted by gender, $b=-2.30, t(99.97)=-3.88, p<.001$. The direction indicates that girls are more likely than boys to use anger-related emotion regulation, as the model's intercept is the mean usage of anger-related emotion regulation of girls, adjusted for the influence of any of the other coping strategies. Additionally, age was a significant predictor for anger-related emotion regulation, $b=0.33, t(100.05)=2.12, p=.037$. As the findings in palliative emotion regulation, older adolescents used anger-related emotion regulation more often than younger ones. The second step of the model led to a $15 \%$ increase in explained variation in anger-related emotion regulation. None of the other models showed any improvement by including gender as a predictor.

\section{Coping Strategies and Gender Role Attitudes (Hypothesis 2)}

To test if GRAs moderate the association between gender and coping strategies, step three included the GRA scales and their interaction with gender. The GRA scales themselves did not significantly predict any coping strategies, and neither did the interaction terms (see Table 3). In none of the models did the third step lead to a significant change in $R^{2}$.

\section{Well-Being and Coping Strategies by Gender (Hypothesis 3)}

To investigate if associations between coping strategies and well-being vary between genders, an additional hierarchical multiple regression with three steps was conducted. Neither age nor the length of stay predicted well-being significantly at step one, but the country of origin did (Table 4).Three of the included coping strategies showed a positive association with well-being at step two: seeking social support, palliative emotion regulation, and avoidance coping. ${ }^{1}$ Therefore, higher well-being was related to increased use of seeking social support, palliative emotion regulation, and avoidance coping. The second step led to a significant increase in $R^{2}$, $F(5,93)=4.17, p=.002$, explaining $16 \%$ more of the variation. Including gender and the interactions of gender with each coping strategy at step three did not improve the model.

\footnotetext{
A sensitivity analysis with centered raw values of the coping strategies provided a slightly different pattern of significances. Again, only step two led to a significant improvement of the model, but only social support was significantly connected to well-being $(p<.001)$.
} 
Table 2. Correlation between variables

\begin{tabular}{|c|c|c|c|c|c|c|c|c|c|c|c|}
\hline Variable & 1 & 2 & 3 & 4 & 5 & 6 & 7 & 8 & 9 & 10 & 11 \\
\hline 1. Gender & 1 & & & & & & & & & & \\
\hline 2. Gender-transcendent & .16 & 1 & & & & & & & & & \\
\hline 3. Gender-linked & .03 & $-.54^{\star}$ & 1 & & & & & & & & \\
\hline 4. Anger-related ER & $-.35^{\star}$ & -.15 & .05 & 1 & & & & & & & \\
\hline 5. Avoidance coping & .01 & .04 & -.12 & -.13 & 1 & & & & & & \\
\hline 6. Social support & -.11 & -.11 & .01 & -.01 & -.15 & 1 & & & & & \\
\hline 7. Problem solving & .05 & .10 & -.07 & -.08 & .10 & $-.29 *$ & 1 & & & & \\
\hline 8. Palliative ER & .01 & -.17 & .16 & .04 & $-.46^{*}$ & $-.18 *$ & $-.44^{\star}$ & 1 & & & \\
\hline 9. Well-being & .01 & .08 & -.01 & -.05 & .02 & .31 & -.03 & .06 & 1 & & \\
\hline 10. Age & .15 & -.05 & .02 & .14 & -.05 & -.13 & -.16 & $.27 *$ & -.18 & 1 & \\
\hline 11. Length of stay & .30 & .08 & .10 & -.11 & -.00 & .02 & .11 & -.06 & .16 & -.05 & 1 \\
\hline
\end{tabular}

Note. $\mathrm{ER}=$ Emotion regulation. ${ }^{\star} p<.05$.

Table 3. Hierarchical regression of anger-related emotion regulation

\begin{tabular}{|c|c|c|c|c|c|c|}
\hline Variable & $B$ & SE B & $\beta$ & $p$ & $R^{2}$ & $\Delta R^{2}$ \\
\hline Step 1 & & & & & 0.03 & \\
\hline Age & 0.25 & 0.17 & .15 & .140 & & \\
\hline LOS & -0.17 & 0.24 & -.08 & .474 & & \\
\hline Syria & -0.29 & 1.04 & -.09 & .780 & & \\
\hline Iraq & -0.92 & 1.09 & -.30 & .398 & & \\
\hline Step 2 & & & & & 0.18 & $0.15^{\star}$ \\
\hline Age & 0.37 & 0.16 & .22 & $.021 *$ & & \\
\hline LOS & 0.08 & 0.23 & .04 & .728 & & \\
\hline Syria & 0.26 & 0.97 & .08 & .788 & & \\
\hline Iraq & -0.63 & 1.01 & -.20 & .533 & & \\
\hline Gender & -2.52 & 0.60 & -.81 & $<.001 *$ & & \\
\hline Step 3 & & & & & 0.19 & 0.01 \\
\hline Age & 0.37 & 0.17 & .22 & $.029 *$ & & \\
\hline LOS & 0.09 & 0.24 & .04 & .711 & & \\
\hline Syria & 0.55 & 1.08 & .18 & .611 & & \\
\hline Iraq & -0.39 & 1.10 & -.13 & .724 & & \\
\hline Gender & -2.48 & 0.63 & -.80 & $<.001 \star$ & & \\
\hline GRA - GT & -0.03 & 0.07 & -.01 & .614 & & \\
\hline GRA - GL & 0.00 & 0.04 & .00 & .993 & & \\
\hline Gender $\times$ GT & 0.01 & 0.09 & .00 & .880 & & \\
\hline Gender $\times \mathrm{GL}$ & -0.01 & 0.06 & -.00 & .871 & & \\
\hline
\end{tabular}

Note. LOS = Length of stay; GRA = Gender Role Attitudes; GT = Gender-Transcendent; GL = Gender-Linked. ${ }^{*} p<.05$

\section{Discussion}

We tested the hypothesis that gender and GRAs were associated with using different coping strategies, namely anger-related emotion regulation, palliative emotion regulation, seeking social support, avoidance coping, and problem-solving, to gain more insight into associations between coping strategies, gender, and GRAs of young refugees. Furthermore, we tested if the gender of young refugees moderated the associations between coping strategies and well-being. Overall, the hypotheses were only partially supported by the present findings. 
Table 4. Hierarchical regression of well-being

\begin{tabular}{|c|c|c|c|c|c|c|c|}
\hline Variable & $B$ & SE B & $t$ & $d f$ & $p$ & $R^{2}$ & $\Delta R^{2}$ \\
\hline Step 1 & & & & & & $0.10 *$ & \\
\hline Intercept & 10.46 & 1.86 & 5.65 & 86.82 & $<.001 *$ & & \\
\hline Age & -0.18 & 0.11 & -1.65 & 96.17 & .102 & & \\
\hline LOS & 0.24 & 0.16 & 1.53 & 53.65 & .133 & & \\
\hline Syria & 1.44 & 0.67 & 2.16 & 97.66 & $.033^{*}$ & & \\
\hline Iraq & 1.20 & 0.71 & 1.69 & 90.88 & .095 & & \\
\hline Step 2 & & & & & & 0.26 & $0.16^{*}$ \\
\hline Intercept & 10.24 & 1.77 & 5.78 & 87.78 & $<.001^{\star}$ & & \\
\hline Age & -0.18 & 0.11 & -1.65 & 92.44 & .102 & & \\
\hline LOS & 0.23 & 0.15 & 1.49 & 42.25 & .143 & & \\
\hline Syria & 1.67 & 0.62 & 2.68 & 92.41 & $.009 *$ & & \\
\hline Iraq & 1.44 & 0.67 & 2.15 & 83.68 & $.034^{\star}$ & & \\
\hline ANG & 0.02 & 0.06 & 0.32 & 82.07 & .752 & & \\
\hline SOC & 0.28 & 0.06 & 4.35 & 92.56 & $<.001 *$ & & \\
\hline AVO & 0.19 & 0.08 & 2.46 & 93.58 & $.016^{*}$ & & \\
\hline PAL & 0.27 & 0.09 & 3.00 & 91.87 & $.003^{*}$ & & \\
\hline PRO & 0.13 & 0.07 & 1.91 & 90.56 & .060 & & \\
\hline Step 3 & & & & & & 0.26 & 0.00 \\
\hline Intercept & 10.30 & 1.85 & 5.56 & 74.56 & $<.001^{\star}$ & & \\
\hline Age & -0.20 & 0.11 & -1.79 & 85.65 & .077 & & \\
\hline LOS & 0.24 & 0.17 & 1.38 & 29.49 & .177 & & \\
\hline Syria & 1.78 & 0.65 & 2.72 & 82.85 & $.008^{*}$ & & \\
\hline Iraq & 1.65 & 0.70 & 2.37 & 71.42 & $.020 *$ & & \\
\hline ANG & 0.03 & 0.07 & 0.41 & 84.61 & .685 & & \\
\hline AVO & 0.18 & 0.08 & 2.29 & 87.25 & $.024^{\star}$ & & \\
\hline SOC & 0.28 & 0.07 & 0.41 & 86.43 & $<.001 *$ & & \\
\hline PRO & 0.12 & 0.07 & 1.73 & 85.01 & .086 & & \\
\hline PAL & 0.25 & 0.10 & 2.62 & 85.01 & $.010^{*}$ & & \\
\hline Gender & 0.11 & 0.46 & 0.23 & 56.12 & .082 & & \\
\hline Gender $\times$ ANG & 0.06 & 0.08 & 0.72 & 82.22 & .476 & & \\
\hline Gender $\times$ AVO & -0.16 & 0.10 & -1.60 & 73.34 & .113 & & \\
\hline Gender $\times$ SOC & -0.01 & 0.09 & -0.14 & 87.23 & .891 & & \\
\hline Gender $\times$ PRO & -0.07 & 0.09 & -0.75 & 83.93 & .457 & & \\
\hline Gender $\times$ PAL & -0.01 & 0.14 & -0.05 & 75.09 & .964 & & \\
\hline
\end{tabular}

Note. LOS = Length of stay; ANG = Anger-related emotion regulation; SOC = Social support; AVO = Avoidance coping; PAL = Palliative emotion regulation; PRO $=$ Problem solving. ${ }^{\star} p \leq .05$.

\section{Gender Differences in the Use of Coping Strategies}

First, to test for associations between gender and coping strategies (Hypothesis 1), gender was included as a predictor for each coping strategy after controlling for age, length of stay, and country of origin. However, the present study could only identify one significant gender difference in coping strategies used by young refugees: Girls used more anger-related emotion regulation than boys. This finding contradicts previous findings by Eschenbeck et al. (2018) and the stereotype of boys showing more aggression than girls but is in line with a finding by Hampel and Petermann
(2006). The authors attribute their findings to a shift in the pattern of girls' use of emotion regulation. Indeed, different studies on emotion regulation strategies of adolescents found that girls shift toward increased use of emotion regulation patterns like venting their anger during puberty (Lange \& Tröster, 2015; Zimmermann \& Iwanski, 2014). Such behavior is covered by the anger-related emotion regulation scale. Lange and Tröster (2015) found this shift to be more pronounced in girls than boys. They attributed the shift to changes caused by puberty, explaining the association between age and anger-related emotion regulation.

Developmental changes are also considered to contribute to age-related increases in palliative emotion regulation, 
a shift found starting in late childhood (Zimmer-Gembeck \& Skinner, 2011). This could explain the positive association between palliative emotion regulation and age found in the present study. The findings suggest that normative developmental aspects should not be neglected in research on the coping of refugee minors. Nonetheless, age was not a significant predictor of the remaining coping strategies. Findings such as an increase in planful problem solving (ZimmerGembeck \& Skinner, 2011) could not be replicated. One possible reason could be the frequent confrontation of young refugees with stressful situations outside their control or of traumatic extent in which case problem solving might not be a helpful way to cope and therefore is less employed (Akgül et al., 2021; Compas et al., 2001).

The failure of replicating any other previous results on gender differences in coping - however, mixed those results may be - was surprising. Different reasons can explain the failure of the present study to do so. First, most studies reported only small effect sizes for gender differences in all coping strategies (Compas et al., 2001; Tamres et al., 2002; for an exception, see Eschenbeck et al., 2018). Moreover, in their cross-cultural study with German and Turkish adolescents, Kohlmann et al. (2012) found the gender difference in seeking social support to be smaller in the Turkish sample than the German one. Hence, the sample size of the present study might not be sufficient for reliable detection of gender differences. Second, low reliabilities lead to biased and underestimated results when researching associations (Schmitt, 1996). Thus, the relatively low internal consistencies of some scales used (e.g., avoidance coping) should prompt caution in interpreting and generalizing the results. Additionally, the measurements used in the present study have not been tested for measurement invariance with members of the researched cultures. Further investigations of measurement invariance are necessary to see what conclusions can be made on their basis (Boer et al., 2018).

\section{Gender Role Attitudes and Coping Strategies}

Although plenty of studies argue that differences in socialization are one possible reason for gender and cultural differences in the use of coping strategies (Al-Bahrani et al., 2013; Alzoubi et al., 2019; Eschenbeck et al., 2012), this assumption has rarely been tested. Therefore, the present study included gender role attitudes to measure associations of social roles and norms with adolescents' coping. Contrary to Hypothesis 2, the GRAs did not moderate the association between gender and coping strategies. Following the attitude-behavior consistency theory (Taylor et al.,
2006), an association between GRA and gendered coping behavior seemed plausible. Bartini's (2006) study on gender flexibility followed this reasoning when measuring the association between attitudes on gender roles and gendered leisure time behavior. She concluded that the connection between attitudes and behavior was not as tight as assumed. A similar result was found regarding gender stereotypes specific to coping behavior. Schmitz et al. (2012) asked adolescents about expectations for gendered use of coping strategies. Their responses revealed a pattern of gender differences consistent with common stereotypes, but these only partially matched the actual use of coping strategies reported by the same adolescents. In line with this, the present findings suggest that gender-role attitudes may not reveal a possible connection between socialization and gender differences. It, therefore, remains unclear to what extent the absence of gender differences in the present study could be due to an actual absence of gender differences in the way participants were socialized.

\section{Gender Differences in the Association Between Coping Strategies and Well-Being}

An additional hierarchical multiple regression for wellbeing was conducted to test possible gender differences in the association between coping strategies and well-being of boys and girls (Hypothesis 3). While neither age nor length of stay predicted young refugees' well-being, the country of origin was associated with well-being. Syrian and Iraqi participants reported more well-being than Afghans. The results indicate the importance of factors connected to the country of origin (e.g., legal status) with participants' well-being after they arrive in the host country (Bronstein \& Montgomery, 2011; Lustig et al., 2004). The second step showed that three coping strategies - seeking social support, avoidance coping, and palliative emotion regulation - were predictors of well-being. The findings contradict several previous ones: First, previous studies found negative associations of age and well-being (Michel et al., 2009; Ravens-Sieberer et al., 2010), which were not replicated in the present study (for a possible explanation, see Fazel et al., 2012). Also contrary to previous studies, avoidance coping was positively related to well-being. Felsten (1998) found more depressive symptoms in men using avoidance coping, suggesting that the strategy is related to decreased well-being. Piko (2001) found the same negative association between avoidance coping and psychological well-being for both genders. The different directions of the relationship could be explained by different behaviors comprising the avoidance coping scales in the present and previous studies. While the scales of 
Felsten (1998) and Piko (2001) include behaviors such as daydreaming, withdrawal, distraction, or criticizing oneself, the avoidance scale of the present study mostly covers cognitive withdrawal. Further, Compas et al. (2001) suggested that judgments of controllability might influence the relationship of avoidance coping with well-being. In addition to the contrary findings, a moderation of the association between any of the coping strategies and well-being by gender was not found.

\section{Limitations}

As the models showed only low explanations of variance, the present study raises the question of other possible predictors and interactions. A wide range of factors associated with the context of forced migration of the participants can influence their well-being (Bronstein \& Montgomery, 2011; Lustig et al., 2004) and their way of coping (Benson et al., 2011). The present study considered those factors only to a limited extent, as the small sample size did not allow to test for interactions of culture by country of origin with gender or gender role attitudes and - moreover - previous traumatic events were not included. Therefore, future studies could add stressful situations more specific to young refugees and coping strategies that have been shown to be often employed by refugees, for example, religious coping (Alzoubi et al., 2019). Furthermore, the present study covered only one potentially stressful situation (argument with a close friend), but context and features of the stressful situation itself might play a role in the use of coping strategies (Compas et al., 2001; Lazarus \& Folkman, 1984). Therefore, following studies should also introduce potentially stressful situations in the context of school, family or related to migration. An additional focus on resources of young refugees like self-esteem (Gestsdottir et al., 2015) would add another piece to understand their adaptation in Germany.

In addition to the already mentioned methodological problems of low internal consistencies and sample size, it is important to highlight possible biases occurring during self-reports of attitudes, gender typical behaviors, and stereotypes (Bartini, 2006; Schmitz et al., 2012) affecting the answers of participants, which could be further enhanced by the culture-specific response patterns (Lalwani et al., 2009; Smith et al., 2016). Additional information from parents or teachers on the preferred coping strategies of adolescents could broaden the understanding of gender differences. The present study does not allow for investigations into these possible biases or cross-cultural interpretations without a suitable comparison group. In conclusion, further investigations should include validating the measurements, larger samples, and comparison groups to allow for conclusions based on different cultural backgrounds.
As few predictors and models in the study reached significance, an investigation into additional predictors is of interest to identify other possible associations with minor refugees' well-being and coping.

\section{Conclusion}

The study gave insight into the coping behavior of young refugees in Germany by identifying a gender difference in the use of anger-related emotion regulation and an increased use of anger-related and palliative emotion regulation in older adolescent refugees. Neither additional associations between gender and coping strategies nor moderation by GRAs could be identified. While these findings are in line with previous studies on emotion regulation, the results still raise questions regarding possible other gender differences and associations to additional predictors. Young refugees using more palliative emotion regulation, social support, and avoidance coping reported higher well-being independently of their age or gender. In general, the study shows how important it is to do research with young refugees without over-generalizing findings from Western samples.

\section{Electronic Supplementary Material}

The electronic supplementary material is available with the online version of the article at https://doi.org/10.1027/ 2512-8442/a000094

ESM 1. Tables E1-E4: The tables display the results of the hierarchical multiple regressions of the remaining coping strategies

\section{References}

Akgül, G., Klimstra, T., \& Cok, F. (2021). The role of coping strategies in interpersonal identity development of waraffected immigrant adolescents. New Directions for Child and Adolescent Development, 2021(176), 103-121. https://doi.org/ 10.1002/cad.20392

Al-Bahrani, M., Aldhafri, S., Alkharusi, H., Kazem, A., \& Alzubiadi, A. (2013). Age and gender differences in coping style across various problems: Omani adolescents' perspective. Journal of Adolescence, 36(2), 303-309. https://doi.org/10.1016/j. adolescence.2012.11.007

Alzoubi, F. A., Al-Smadi, A. M., \& Gougazeh, Y. M. (2019). Coping strategies used by Syrian refugees in Jordan. Clinical Nursing Research, 28(4), 396-421. https://doi.org/10.1177/ 1054773817749724

Baber, K. M., \& Tucker, C. J. (2006). The Social Roles Questionnaire: A new approach to measuring attitudes toward gender. Sex Roles, 54(7-8), 459-467. https://doi.org/10.1007/s11199006-9018-y 
Barry, D. T., \& Beitel, M. (2006). Sex role ideology among East Asian immigrants in the United States. The American Journal of Orthopsychiatry, 76(4), 512-517. https://doi.org/10.1037/00029432.76.4.512

Bartini, M. (2006). Gender role flexibility in early adolescence: Developmental change in attitudes, self-perceptions, and behaviors. Sex Roles, 55(3-4), 233-245. https://doi.org/ 10.1007/s11199-006-9076-1

Beck, J., Lange, S., \& Tröster, H. (2016). Geschlechtsunterschiede in der Stressvulnerabilität, Stressbewältigung und Stresssymptomatik bei Grundschulkindern [Gender differences in stress vulnerability, coping strategies, and stress symptoms in childhood]. Zeitschrift für Gesundheitspsychologie, 24(3), 145-155. https://doi.org/10.1026/0943-8149/a000165

Benson, M. A., Compas, B. E., Layne, C. M., Vandergrift, N., Pašalić, H., Katalinksi, R., \& Pynoos, R. S. (2011). Measurement of post-war coping and stress responses: A study of Bosnian adolescents. Journal of Applied Developmental Psychology, 32(6), 323-335. https://doi.org/10.1016/j.appdev.2011.07.001

Boer, D., Hanke, K., \& He, J. (2018). On detecting systematic measurement error in cross-cultural research: A review and critical reflection on equivalence and invariance tests. Journal of Cross-Cultural Psychology, 49(5), 713-734. https://doi.org/ 10.1177/0022022117749042

Brems, C., \& Johnson, M. E. (1989). Problem-Solving appraisal and coping style: The influence of sex-role orientation and gender. The Journal of Psychology, 123(2), 187-194. https://doi. org/10.1080/00223980.1989.10542975

Broderick, P. C., \& Korteland, C. (2002). Coping style and depression in early adolescence: Relationships to gender, gender role, and implicit beliefs. Sex Roles, 46(7/8), 201-213. https://doi. org/10.1023/A:1019946714220

Bronstein, I., \& Montgomery, P. (2011). Psychological distress in refugee children: A systematic review. Clinical Child and Family Psychology Review, 14(1), 44-56. https://doi.org/10.1007/ s10567-010-0081-0

Cavallo, F., Dalmasso, P., Ottová-Jordan, V., Brooks, F., Mazur, J., Välimaa, R., Gobina, I., Gaspar de Matos, M., \& Raven-Sieberer, U. (2015). Trends in life satisfaction in European and NorthAmerican adolescents from 2002 to 2010 in over 30 countries. European Journal of Public Health, 25(Suppl 2), 80-82. https:// doi.org/10.1093/eurpub/ckv014

Cicognani, E. (2011). Coping strategies with minor stressors in adolescence: Relationships with social support, self-efficacy, and psychological well-being. Journal of Applied Social Psychology, 41(3), 559-578. https://doi.org/10.1111/j.15591816.2011.00726.x

Compas, B. E., Connor-Smith, J. K., Saltzman, H., Thomsen, A. H., \& Wadsworth, M. E. (2001). Coping with stress during childhood and adolescence: Problems, progress, and potential in theory and research. Psychological Bulletin, 127(1), 87-127. https:// doi.org/10.1037/0033-2909.127.1.87

Copeland, E. P., \& Hess, R. S. (1995). Differences in young adolescents' coping strategies based on gender and ethnicity. Journal of Early Adolescence, 15(2), 203-219. https://doi.org/ 10.1177/2F0272431695015002002

Eschenbeck, H. (2010). Bewältigung alltäglicher Stresssituationen von Kindern und Jugendlichen [Coping with daily stressors in children and adolescents: The influence of stressful situation, age, and gender]. Zeitschrift für Gesundheitspsychologie, 18(3), 103-118. https://doi.org/10.1026/0943-8149/a000018

Eschenbeck, H., Heim-Dreger, U., Tasdaban, E., Lohaus, A., \& Kohlmann, C.-W. (2012). A Turkish adaptation of the coping scales from the German Stress and Coping Questionnaire for Children and Adolescents. European Journal of Psychological
Assessment, 28(1), 32-40. https://doi.org/10.1027/1015-5759/ a000088

Eschenbeck, H., Kohlmann, C.-W., \& Lohaus, A. (2007). Gender differences in coping strategies in children and adolescents. Journal of Individual Differences, 28(1), 18-26. https://doi.org/ 10.1027/1614-0001.28.1.18

Eschenbeck, H., Kohlmann, C.-W., Lohaus, A., \& Klein-Heßling, J. (2006). Die Diagnostik von Stressbewältigung mit dem "Fragebogen zur Erhebung von Stress und Stressbewältigung im Kindes- und Jugendalter" (SSKJ 3-8) [The assessment of coping with the "Questionnaire for the Measurement Stress and Coping in Children and Adolescents (SSKJ 3-8)": Factors and psychometric analyses]. Diagnostica, 52(3), 131-142. https://doi.org/10.1026/0012-1924.52.3.131

Eschenbeck, H., Schmid, S., Schröder, I., Wasserfall, N., \& Kohlmann, C.-W. (2018). Development of coping strategies from childhood to adolescence. European Journal of Health Psychology, 25(1), 18-30. https://doi.org/10.1027/2512-8442/a000005

Fazel, M., Reed, R. V., Panter-Brick, C., \& Stein, A. (2012). Mental health of displaced and refugee children resettled in high-income countries: Risk and protective factors. The Lancet, 379(9812), 266-282. https://doi.org/10.1016/S0140-6736(11)60051-2

Felsten, G. (1998). Gender and coping: Use of distinct strategies and associations with stress and depression. Anxiety, Stress, \& Coping, 11(4), 289-309. https://doi.org/10.1080/10615809808248316

Gestsdottir, S., Arnarsson, A., Magnusson, K., Arngrimsson, S. A., Sveinsson, T., \& Johannsson, E. (2015). Gender differences in development of mental well-being from adolescence to young adulthood: An eight-year follow-up study. Scandinavian Journal of Public Health, 43(3), 269-275. https://doi.org/10.1177/ 1403494815569864

Hampel, P., \& Petermann, F. (2005). Age and gender effects on coping in children and adolescents. Journal of Youth and Adolescence, 34(2), 73-83. https://doi.org/10.1007/s10964005-3207-9

Hampel, P., \& Petermann, F. (2006). Perceived stress, coping, and adjustment in adolescents. The Journal of Adolescent Health 38(4), 409-415. https://doi.org/10.1016/j.jadohealth.2005.02.014

Hobfoll, S. E., Dunahoo, C. L., Ben-Porath, Y., \& Monnier, J. (1994). Gender and coping: The dual-axis model of coping. American Journal of Community Psychology, 22(1), 49-82. https://doi.org/ 10.1007/BF02506817

Hynie, M. (2018). The social determinants of refugee mental health in the post-migration context: A critical review. Canadian Journal of Psychiatry/Revue Canadienne de Psychiatrie, 63(5), 297-303. https://doi.org/10.1177/0706743717746666

Kohlmann, C.-W., Eschenbeck, H., Heim-Dreger, U., \& Tasdaban, E. (2012). Stressbewältigung von Kindern und Jugendlichen in Deutschland und der Türkei: Interkulturelle Unterschiede in der Suche nach sozialer Unterstützung? [Coping in children and adolescents in Germany and Turkey: Cultural differences in seeking social support?] Zeitschrift für Gesundheitspsychologie, 20(1), 22-26. https://doi.org/10.1026/0943-8149/a000058

Lalwani, A. K., Shrum, L. J., \& Chiu, C.-Y. (2009). Motivated response styles: The role of cultural values, regulatory focus, and self-consciousness in socially desirable responding. Journal of Personality and Social Psychology, 96(4), 870-882. https://doi.org/10.1037/a0014622

Lange, S., \& Tröster, H. (2015). Adaptive und maladaptive Emotionsregulationsstrategien im Jugendalter [Adaptive and Maladaptive Emotion Regulation Strategies in Adolescence]. Zeitschrift für Gesundheitspsychologie, 23(3), 101-111. https:// doi.org/10.1026/0943-8149/a000141

Lazarus, R. S., \& Folkman, S. (1984). Stress, appraisal, and coping (11th ed.). Springer. 
Lustig, S. L., Kia-Keating, M., Grant Knight, W., Geltman, P., Ellis, H., Kinzie, J., Keane, T., \& Saxe, G. N. (2004). Review of child and adolescent refugee mental health. Journal of the American Academy of Child and Adolescent Psychiatry, 43(1), 24-36. https://doi.org/10.1097/00004583-200401000-00012

Malooly, A. M., Flannery, K. M., \& Ohannessian, C. M. (2017). Coping mediates the association between gender and depressive symptomatology in adolescence. International Journal of Behavioral Development, 41(2), 185-197. https://doi.org/ 10.1177/0165025415616202

Michel, G., Bisegger, C., Fuhr, D. C., \& Abel, T. (2009). Age and gender differences in health-related quality of life of children and adolescents in Europe: A multilevel analysis. Quality of Life Research, 18(9), 1147-1157. https://doi.org/10.1007/s11136009-9538-3

Persike, M., \& Seiffge-Krenke, I. (2016). Stress with parents and peers: How adolescents from 18 nations cope with relationship stress. Anxiety, Stress, and Coping, 29(1), 38-59. https://doi. org/10.1080/10615806.2015.1021249

Piko, B. (2001). Gender differences and similarities in adolescents' way of coping. The Psychological Record, 51, 223-235. https:// doi.org/10.1007/BF03395396

R Core Team. (2020). R: A language and environment for statistical computing (Version 4.0.3) [Computer software]. R Foundation for Statistical Computing. https://www.R-project.org/

Ravens-Sieberer, U., Erhart, M., Rajmil, L., Herdman, M., Auquier, P., Bruil, J., Power, M., Duer, W., Abel, T., Czemy, L., Mazur, J., Czimbalmos, A., Tountas, Y., Hagquist, C., \& Kilroe, J. (2010). Reliability, construct and criterion validity of the KIDSCREEN10 Score: A short measure for children and adolescents' aellbeing and health-related quality of life. Quality of Life Research: An International Journal of Quality of Life Aspects of Treatment, Care and Rehabilitation, 19(10), 1487-1500. https://doi.org/ 10.1007/s11136-010-9706-5

Ryan, R. M., \& Deci, E. L. (2001). On happiness and human potentials: A review of research on hedonic and eudaimonic well-being. Annual Review of Psychology, 52, 141-166. https:// doi.org/10.1146/annurev.psych.52.1.141

Schmitt, N. (1996). Uses and abuses of coefficient alpha. Psychological Assessment, 8(4), 350-355. https://doi.org/ 10.1037/1040-3590.8.4.350

Schmitz, A.-K., Vierhaus, M., \& Lohaus, A. (2012). Geschlechtstypische Unterschiede und geschlechtstypische Erwartungen beim Einsatz von Bewältigungsstrategien und ihre Zusammenhänge zum Problemverhalten von Jugendlichen [Sex differences and sex-related expectancies regarding the use of coping strategies and their relations to adolescents' problem behavior]. Zeitschrift für Gesundheitspsychologie, 20(1), 13-21. https://doi.org/10.1026/0943-8149/a000060

Smith, P. B., Vignoles, V. L., Becker, M., Owe, E., Easterbrook, M. J., Brown, R., Bourguignon, D., Garđarsdóttir, R. B., Kreuzbauer, R., Cendales Ayala, B., Yuki, M., Zhang, J., Lv, S., Chobthamkit, P., Jaafar, J. L., Fischer, R., Milfont, T. L., Gavreliuc, A., Baguma, P., ... Harb, C. (2016). Individual and culturelevel components of survey response styles: A multi-level analysis using cultural models of selfhood. International Journal of Psychology/Journal International de Psychologie, 453463. https://doi.org/10.1002/ijop.12293

Tamres, L. K., Janicki, D., \& Helgeson, V. S. (2002). Sex differences in coping behavior: A meta-analytic review and an examination of relative coping. Personality and Social Psychology Review, 6(1), 2-30. https://doi.org/10.1207/S15327957PSPR0601_1

Taylor, S. E., Peplau, L. A., \& Sears, D. O. (2006). Social psychology (12th ed.). Pearson.
Torsheim, T., Ravens-Sieberer, U., Hetland, J., Välimaa, R., Danielson, M., \& Overpeck, M. (2006). Cross-national variation of gender differences in adolescent subjective health in Europe and North America. Social Science \& Medicine, 62(4), 815-827. https://doi.org/10.1016/j.socscimed.2005.06.047

Van Buuren, S., \& Groothuis-Oudshoorn, K. (2011). MICE: Multivariate imputation by chained equations in R. Journal of Statistical Software, 45(3), 1-67. https://doi.org/10.18637/jss. v045.i03

Washburn-Ormachea, J. M., Hillman, S. B., \& Sawilowsky, S. S. (2004). Gender and gender-role orientation differences on adolescents' coping with peer stressors. Journal of Youth and Adolescence, 33(1), 31-40. https://doi.org/10.1023/A:1027330213113

Wilson, G. S., Pritchard, M. E., \& Revalee, B. (2005). Individual Differences in Adolescent Health Symptoms: The Effects of Gender and Coping. Journal of Adolescence, 28(3), 369-379. https://doi.org/10.1016/j.adolescence.2004.08.004

Zimmer-Gembeck, M. J., \& Skinner, E. A. (2011). The development of coping across childhood and adolescence: An integrative review and critique of research. International Journal of Behavioral Development, 35(1), 1-17. https://doi.org/10.1177/ 0165025410384923

Zimmermann, P., \& Iwanski, A. (2014). Emotion regulation from early adolescence to emerging adulthood and middle adulthood. International Journal of Behavioral Development, 38(2), 182-194. https://doi.org/10.1177/0165025413515405

\section{History}

Received March 5, 2021

Revision received June 11, 2021

Accepted July 12, 2021

Published online January 28, 2022

\section{Conflict of Interest}

We have no conflict of interest to disclose.

\section{Publication Ethics}

Ethical approval was issued for the project by the Ethics Commission of Bielefeld University.

\section{Open Data}

In line with the funding guidelines, all data parts of the project will be available upon request at the end of the YOURHEALTH project.

\section{Funding}

The project YOURGRWOTH is part of the YOURHEALTH project funded by the BMBF (Federal Ministry of Education and Research). Funding code: 01GL1749A. Open access publication enabled by Bielefeld University.

\section{ORCID}

Hannah Nilles

(iD) https://orcid.org/0000-0003-1137-0050

Pia Schmees

(D)https://orcid.org/0000-0001-8763-6578

\section{Hannah Nilles}

AE03 - Developmental Psychology

Faculty of Psychology and Sports Science

Universitätsstraße 25

33615 Bielefeld

Germany

hannah.nilles@uni-bielefeld.de 